\title{
Design e Antropologia na valorização da produção artesanal ceramista da Comunidade Quilombola Negros do Riacho - RN
}

\author{
Design and Anthropology in the valorization of artisanal ceramist production of the \\ Quilombola Community Negros do Riacho - RN
}

SANTOS, Layanne Ferreira dos; Bacharel em Design; Universidade Federal do Rio Grande do Norte layannefs|@gmail.com

OLIVEIRA, Lorena Gomes Torres de; Doutoranda em Design pela Universidade de Lisboa; Universidade Federal do Rio Grande do Norte

lorenagomestorres@gmail.com

\begin{abstract}
Resumo
Este estudo apresenta o desenvolvimento de ações em Design para valorização da produção artesanal ceramista da Comunidade Quilombola Negros do Riacho localizada no município de Currais Novos, interior do Rio Grande do Norte. A comunidade tem o artesanato de cerâmica como elemento importante da sua identidade cultural e fonte de renda complementar. Buscando a valorização da produção e dessa forma promover o desenvolvimento e continuação de marca cultural da comunidade, foram desenvolvidas duas ações em Design por meio de ferramentas de design, design e antropologia e do design etnográfico. A primeira ação teve como resultado o reconhecimento da comunidade, da produção e dos atores que a configuram. A segunda ação resultou no desenvolvimento de um artefato artesanal por meio do design, um Veículo de Tração Humana - VTH, com o objetivo de auxiliar na tarefa de extração do barro na produção artesanal da cerâmica.
\end{abstract}

Palavras Chave: design e antropologia; artesanato; quilombolas.

\begin{abstract}
This study presents the development of actions in a remaining quilombo Negros do Riacho community in the city of Currais Novos, in the interior of Rio Grande do Norte. The community has ceramic craft as an important element of their cultural identity and source of income. Seeking the production and expansion of a cultural community culture, by design methods, design anthropology and ethnographic design. The first action resulted in the recognition of the community, the production and the actors that shape it. The second action we created a craft artifact throught design methods, a vehicle traction mechanics, in the order to assisting of extracting clay in the production of ceramic craft.
\end{abstract}

Keywords : design and anthropology; crafts; quilombolas 


\section{Introdução}

$\mathrm{Na}$ contemporaneidade o design tem configuração diversa, marcado e constituído pelo rompimento de fronteiras com inúmeras possibilidades de integração entre as diversas áreas dialógicas a esse campo. O design é um universo plural, aberto, amplo e fértil (MOURA 2010). Assim, o design acaba por incorporar diversas áreas do conhecimento na realização de suas análises e de seus projetos, apropriando-se e combinando esses conhecimentos por meio de sua práxis (BONFIM, 1997 apud ALVES, 2016).

Para este estudo foram trabalhadas as relações entre design/artesanato e design/ antropologia. A relação entre design e artesanato vem sendo discutida desde os meados da década de 1970 com Aloísio Magalhães na presidência do IPHAN - Instituto do Patrimônio Histórico e Artístico Nacional (NORONHA et al, 2015). Segundo Anastassakis (2017), foi Aloísio Magalhães junto com a arquiteta e designer Lina Bo Bardi que trouxeram o primeiro "olhar antropológico" para o design no Brasil e uma relação com as raízes do país e o artesanato, Magalhães e Bo Bardi trazem uma sensibilidade antropológica, embora não falassem especificamente de antropologia, conectando o design e artesanato de uma forma muito intensa. A partir deste contexto, a relação de complementaridade entre design e artesanato brasileiro, resulta vários em projetos de pesquisa, produções coletivas, e engajamento mútuo entre o designer e artesão (ANASTASSAKIS, 2017).

Com respeito das intervenções que o design pode fazer no artesanato, Barroso (1999) afirma que as mesmas devem objetivar o desenvolvimento e melhoria da qualidade da competitividade do produto de origem artesanal, de modo sustentável (BARROSO, 1999 apud ALMEIDA, 2010). De acordo com o autor às intervenções podem ser feitas por meio de diagnósticos, pesquisas e informações técnicas, design e desenvolvimento de novos produtos, transferência de tecnologia, testes e experimentações, capacitação e aperfeiçoamento de recursos humanos, promoção, divulgação e comercialização de sua produção (BARROSO, 1999 apud ALMEIDA, 2010).

Ao encontro do que Barroso (1999) defende, Krucken (2009) escabele ações essenciais que podem fomentar a valorização de produtos artesanais e do território. Segundo a autora a qualidade de um produto envolve três elementos: o território, os recursos utilizados e a comunidade que o produziu. “Essa visão é crucial para planejar estratégias de valorização de produtos que promovam o desenvolvimento local." (KRUCKEN, 2009, p. 30). 
A união desses três elementos forma o conceito de terroir ${ }^{1}$, definido como: "o espaço geográfico no qual os valores patrimoniais são frutos de relações complexas das características culturais, sociais, ecológicas e econômicas, tecidas ao longo do tempo." (BRODHAG, 2000 apud KRUCKEN, 2009).

Nessa perspectiva, procurando compreender as relações complexas que caracterizam o território, a identidade cultural e produção artesanal da cerâmica na comunidade, o presente estudo propõe o diálogo entre antropologia e design. A abordagem antropológica em conjunto com o design resulta em um campo híbrido que fomenta o embasamento teórico, bem como o desenvolvimento do processo metodológico da pesquisa.

Dessa forma, a presente estudo é resultado de uma longa pesquisa desenvolvida no grupo de pesquisa ECOAR - Design, Inovação e Sustentabilidade e na disciplina de projeto de produto VI, resultando no trabalho de conclusão de curso da autora. Dessa forma, o estudo relata a experiência do desenvolvimento de ações em design para produção ceramista da Comunidade Quilombola Negros do Riacho, fazendo uso de ferramentas do design anthropology, da etnografia aplicada ao design e da ergonomia. Foram desenvolvidas duas ações propostas por Lia Krucken (2009): Reconhecer a qualidade do território e Desenvolver novos produtos e serviços que respeitem a vocação e valorizem o território.

\section{Design e Antropologia em um mesmo patamar}

O termo antropologia tornou-se recorrente no campo do design, seja no mercado ou na esfera acadêmica, promovendo uma perspectiva de vários diálogos entre as duas áreas.

De acordo com Anastassakis (2016), é preciso combinar os modos de produção de conhecimento próprios da antropologia e do design e tentar entender como pode surgir uma prática que está entre as duas áreas, criando uma tendência e não um novo campo, onde existe a soma de dois saberes criando um terceiro espaço. Trata-se de uma tentativa bastante nova:

Nos últimos anos, o design incorporou o conhecimento antropológico como parte do processo de pesquisa para uma abordagem etnográfica centrada no usuário, buscando informações mais precisas sobre suas necessidades e experiências. A antropologia, por sua vez, se aproximou do

\footnotetext{
${ }^{1} \mathrm{O}$ francês terrior significa território em português.
} 
design como objeto de análise, a partir da antropologia crítica do design, além de utilizá- lo como inspiração para desafiar os métodos clássicos de trabalho de campo (ANASTASSAKIS et al, 2016, p. 77).

Para Laplantine (2003), o homem nunca parou de se interrogar sobre si mesmo: “A reflexão do homem sobre o homem e sua sociedade, e a elaboração de um saber são, portanto, tão antigos quanto a humanidade" (LAPLANTINE, 2003. p.7). Segundo o autor, a abordagem antropológica só pode ser considerada como tal se for integrativa e tenha o objetivo de considerar as mais diversas dimensões do ser humano em sociedade. Na sua convicção, a antropologia deve ajudar os atores sociais, como economistas, políticos, agrônomos, entre outros, que trabalham na transformação das sociedades que estudam: "Auxiliar uma determinada cultura na explicitação para ela mesma de sua própria diferença é uma coisa; organizar política, econômica e socialmente a evolução dessa diferença é uma outra coisa" (LAPLANTINE, 2003, p.19). Dessa forma, considerando o designer como um ator social, a antropologia pode contribuir no design por meio de suas reflexões e métodos para interpretar a sociedade.

Já o antropólogo brasileiro, Marco Antonio Gonçalves (2000), afirma que a antropologia atrai profissionais de outras áreas porque é um campo que busca o diálogo que engendra uma aparente proximidade com a vida, "a característica de lidar com o particular e o modo com que realiza a pesquisa baseada no trabalho de campo que parecem ser o que mais atrai as pessoas para a antropologia" (Gonçalves, 2010, p. 7).

Diante disso, como o presente estudo procurou, a partir do desenvolvimento de ações, compreender o comportamento, a identidade cultural, o repasse da técnica artesanal entre as gerações e como se constitui o processo de produção das peças, serão apresentadas a seguir definições mais específicas da antropologia cultural segundo Laplantine (2003, p. 97):

1) Estudar os caracteres distintivos das condutas dos seres humano pertencendo a uma mesma cultura, considerada como uma totalidade irredutível à outra.

2) Ela conduz essa pesquisa a partir da observação direta dos comportamentos dos indivíduos, tais como se elaboram em interação com o grupo e o meio no qual nascem e crescem estes indivíduos. Procurando compreender a natureza dos processos de aquisição e transmissão, pelo indivíduo, de uma cultura.

3) Estuda o social em sua evolução, e particularmente sob o ângulo dos processos de contato, difusão, interação e aculturação, isto é, de adoção (ou imposição) das normas de uma cultura por outra. (LAPLANTINE, 2003, 97) 
Do que diz respeito à cultura, é difícil dar uma definição que seja absolutamente satisfatória (LAPLANTINE, 2003). Kroeber, um dos mestres da antropologia americana, levantou mais de 50. Laraia (2001) propõe uma dessas definições:

\begin{abstract}
O homem é o resultado do meio cultural em que foi socializado. Ele é um herdeiro de um longo processo acumulativo, que reflete o conhecimento e a experiência adquirida pelas numerosas gerações que o antecederam. A manipulação adequada e criativa desse patrimônio cultural permite as inovações e as invenções. Estas não são, pois, o produto da ação isolada de um gênio, mas o resultado do esforço de toda uma comunidade. (LARAIA, 2001, p. 45)
\end{abstract}

Laraia (2001), também mostra a definição de cultura sob a ótica de teorias que considera a cultura como sistemas simbólicos. Segundo o autor, Claude LéviStrauss define cultura como "um sistema simbólico que é uma criação acumulativa da mente humana" (LARAIA, 2001, p. 64). Clifford Geertz, antropólogo americano, que considera que a antropologia busca interpretações, a definição de homem é baseada na definição de cultura, o conceito de cultura para Geertz, é essencialmente semiótico: "o homem é um animal amarrado às teias de significados que ele mesmo teceu" (Geertz,1989, p.15).

No que diz respeito da origem dessa relação, alguns historiadores defendem que é entorno dos estudos ergonomia que começa uma aproximação entre as duas áreas. Para pensar a relação homem-máquina e a relação homem e artefatos, é preciso entender a cultura. Segundo Anastassakis (2017), o corpo não é uma coisa dissociada da cultura, portanto alguns designers nos anos 60 fazem uma aproximação com a antropologia para entender corpo humano, este entendido como corpo cultural, pois é moldado pela cultura.

Ainda segunda a autora, a pesquisadora britânica Addison Clark presidente da Fundação Victor Papanek, vêm fazendo uma historiografia dessa aproximação, parte dela é chamada Design Anthropology e surgiu em razão da emergência de uma cultura crítica no campo do design, que questionava a própria prática da disciplina em suas relações com a sociedade. Segundo, Clarke (2011), o livro do designer Victor Papanek, "Design for a real world" teve papel fundamental nesse contexto. Papanek aponta para a antropologia como uma solução para condição alienada da qual toda uma geração de designers desiludidos sentia estar aprisionada. Assim, o livro, explicitava o que seria um dos grandes dilemas dos designers no século XX: sua inconsciência quanto às responsabilidades morais e sociais envolvidas na prática profissional. Além disso, o que tornou o interesse de Papanek pela antropologia uma influência tão efetiva em meio a comunidade de 
designers é sua habilidade de aplicar princípios de análise dos objetos e da cultura material em sua cultura, bem como nas demais. Dessa forma, ele conseguia revelar, em suas observações, as peculiaridades do design (CLARK 2011, apud ANASTASSAKIS, 2012).

\subsection{Design Anthropology}

O Design Anthropology emerge como um campo em que o design e antropologia estão alicerçados em um mesmo patamar, oferecendo uma visão mais crítica dos processos sem que a antropologia cumpra apenas um papel meramente instrumental. Para Gunn e Donovan (2016), o design e a antropologia podem beneficiar-se mutuamente, pois cada disciplina tem sua própria metodologia e identidade, buscando instigar diferentes formas de projeto em situações emergentes (GUUN;DONOVAN, 2016). Anastassakis e Kuschnir apontam algumas definições dessa abordagem híbrida: “[...] o Design Anthropology envolve formas intervencionistas de pesquisa e projeto em campo, trabalho realizado através de ciclos iterativos de reflexão e ação, combinando procedimentos, métodos e ferramentas das duas áreas, design e antropologia" (ANASTASSAKIS \& KUSCHNIR, 2014, p.7)

Para Ingold (2013), o design tem que corresponder ao mundo, ou seja, "abrir nossa percepção ao que está acontecendo lá fora, para que, por sua vez, possamos responder a ela" (INGOLD, 2013 apud PORTO, 2017, p. 77). Diante disso, a incorporação do conhecimento antropológico pelo design surgiu como parte do processo de pesquisa para uma abordagem etnográfica centrada no usuário, buscando informações mais precisas sobre suas necessidades e experiências. A antropologia, por sua vez, se aproximou do design como objeto de análise, a partir da antropologia crítica do design, além de utilizá-lo como inspiração para desafiar os métodos clássicos de trabalho de campo. Assim, o Design Anthropology surge como uma combinação dos modos de produção do conhecimento, com práticas próprias de pesquisa e posicionamento no cenário de atuação, o autor propõe uma antropologia por meio do design é o que ele chama de correspondência, uma chave para repensar tanto o design com a antropologia (PORTO et al, 2017,p.77).

Anastassakis (2017), a partir dos estudos de Ingold também defende essa correspondência entre os dois campos de conhecimento: "design e antropologia como práticas de correspondência". Para a autora essa correspondência significa outra coisa senão projetar, o que significa questionar, utilizando as ferramentas do design, quais são os desafios que atingem as pessoas. Para isso é 
preciso aproximar-se das pessoas correspondendo junto a elas o desafio que enfrentam, ou seja, o designer corresponde àquilo que às afeta e é preciso deixar-se afetar também (ANASTASSAKIS, 2017 Gunn e Donovan (2013), utilizam o DA em maiúsculo referindo-se as disciplinas de design e antropologia estão envolvidas no mesmo patamar, em uma convergência de esforços aprendendo e correspondendo entre si, e não uma estando a serviço da outra (ANASTASSAKIS, 2017).

O Design Anthropology também é um processo colaborativo que envolve as pessoas no processo social de imaginação coletiva através de artefatos mediadores que provoquem a reflexão e estimulem diálogos e discussões mediante a prática, que se modifica na continuidade de ideias em transformação. Otto e Smith (2013) apontam que um dos desafios dessa experimentação de antropologia projetual é desenvolver ferramentas e práticas para a criação colaborativa de futuros possíveis, além de métodos de intervenção, articulados por equipes multidisciplinares em processos de design e inovação.

No tocante dessas ferramentas, uma das sugestões desse novo campo é a substituição de protótipos por "provótipos". O protótipo utiliza-se da experiência do usuário com o objeto na intenção de gerar um fechamento do seu projeto, o foco final é a coisa projetada. Já os provótipos são usados como catalisadores no engajamento dos atores com a linguagem do design. Dessa forma, os provótipos são mediadores que provocam reflexão sobre as questões levantadas pelos pesquisadores na busca por soluções para problemas não dados, mas latentes (MORGENSEN apud GUNN \& DONOVAN, 2016, p.123). Sendo assim, a ênfase no Design Anthropology é dada ao processo e não aos fins, ainda que se deseje chegar a uma solução em forma de produto ou serviço como é o caso desta pesquisa.

\subsubsection{Etnografia aplicada ao Design}

A etnografia é um método de pesquisa qualitativa oriundo da antropologia resultado direto do trabalho de campo, ou seja, é a tradução da experiência em significado. O surgimento da pesquisa etnográfica foi um marco na prática da antropologia, por enfatizar a ideia de tentar entender o pensamento do outro. "[...] Ao compreender o que é a etnografia, ou mais exatamente, o que é a prática da etnografia, é que se pode começar a entender o que representa a análise antropológica como forma de conhecimento" (GEERTZ, 1989, p. 4)

Segundo Laplantine (2003), a etnografia não consiste apenas em coletar uma grande 
quantidade de informações, mas inserir-se no cotidiano e valores de uma determinada sociedade, numa experiência de imersão total, consistindo numa verdadeira aculturação invertida, é necessário interiorizar-se nas significações que os próprios indivíduos atribuem a seus comportamentos.

Esses objetivos da etnografia levaram diversas áreas do conhecimento a adotarem os princípios dos seus métodos com o propósito de conhecer melhor o homem sob diferentes perspectivas. No contexto do design, essa aproximação surgiu durante a década de 1960, os designers, assim como os etnógrafos, necessitam estar imersos nas situações da vida real para coletar insights sobre experiências e significados que formam a base da reflexão, imaginação e do próprio design (OTTO e SMITH, 2013). Essa relação entre design e etnografia inaugurou a abordagem conhecida como design etnográfico. De acordo com o Design Management Institute (DMI), o design etnográfico é:

É uma maneira de entender as particularidades do dia-a-dia de forma a melhorar a probabilidade de sucesso de um novo produto ou serviço. Ou, ainda mais apropriadamente, reduzir a probabilidade de fracasso especialmente no que diz respeito ao entendimento dos comportamentos básicos e contextos dos consumidores. (DMI - Design Management Institute apud ALVES, 2016)

Segundo Murphy e Marcus (2013), a pesquisa etnográfica aplicada ao design, possibilita a familiaridade com o que nos é estranho e um estranhamento com o que nos é familiar, por meio de técnicas e metodologias, o design etnográfico possibilita exercer, de forma consciente e intencional, o distanciamento do olhar desconstruindo pré-noções e preconceitos. Para os autores, tanto o design quanto a etnografia são centrados nas pessoas e estão abertos para reflexividade. Ademais, a etnografia fornece ao design um tipo de engajamento teórico diferente e a transformação da natureza de colaboração no trabalho de design, infundindo uma orientação para a participação (MURPHY; MARCUS, 2013).

Já para O’Grady (2006), a etnografia realizada por designers é uma pesquisa estratégica focada na conexão entre comportamento humano e cultural. O autor defende que a etnografia é um método de pesquisa qualitativa, no entanto, as observações e interpretações do pesquisador são subjetivas e podem ser mais valiosos do qualquer dado qualitativo ou objetivo que possa existir sobre a comunidade escolhida.

A respeito às técnicas de coleta de informação da etnografia, O’Grady (2006) defende que é por meio da triangulação de três diferentes técnicas se encontra a "verdade". Essa triangulação é o processo de combinar diferentes métodos de pesquisa para examinar o mesmo tópico, e assim dar 
mais credibilidade aos resultados encontrados na pesquisa, pois segundo o autor, bons pesquisadores usam diferentes ferramentas para documentar as experiências. Na figura 1 apresentada a seguir, o pesquisador escolheu realizar o cruzamento de três técnicas principais, a observação participante, a revisão bibliográfica e as entrevistas.

Figura 1: Combinação de técnicas etnográficas.

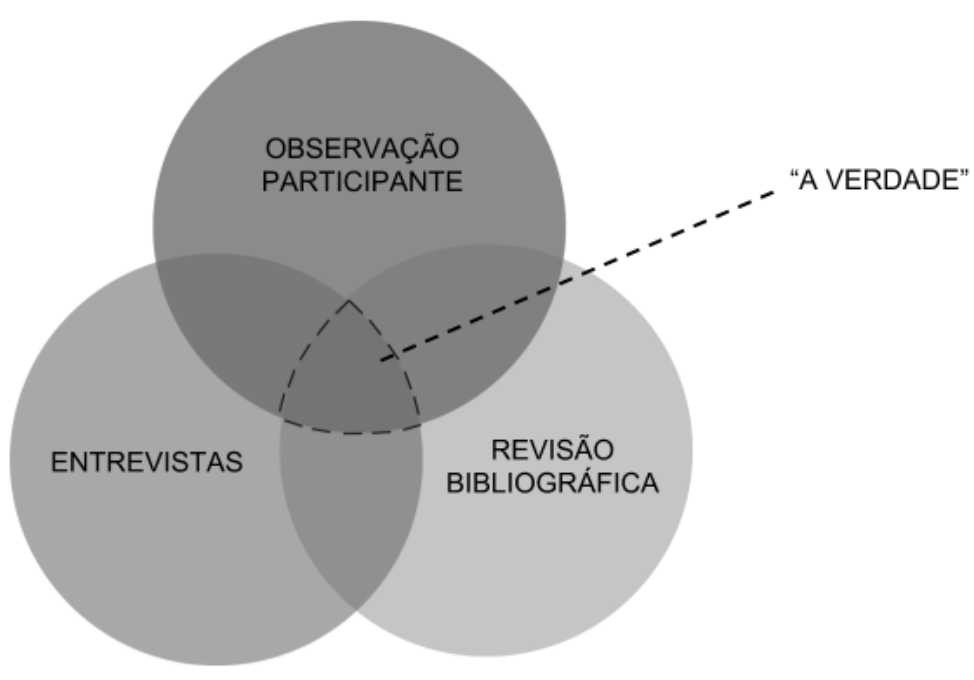

Fonte: Adaptada pela autora a partir de O'Grady, 2016.

\section{Ações em Design para valorização da produção artesanal da cerâmica}

O município de Currais Novos está localizado na microrregião Seridó oriental com a mesorregião central potiguar, distante de Natal, capital do estado do Rio Grande do Norte, 172 km. A 12 quilômetros do município de Currais Novos-RN está situada a comunidade quilombola Negros do Riacho. A comunidade é constituída de remanescentes de quilombolas. O povoado é descendente de Trajano Lopes da Silva, também chamado de "Trajano Passarinho", um ex-escravo que se apossou das terras do Riacho, passando a viver ali com sua família (ASSUNÇÃO, 1994). No Rio Grande do Norte, há 15 comunidades reconhecidas pela FCP- Fundação Cultural Palmares como "remanescentes de quilombo", no entanto, o Centro de Cartografia Aplicada e Informação Geográfica da Universidade de Brasília identificou a existência de 64 agrupamentos, dos quais nenhum possui título coletivo da terra. No caso específico do município de Currais Novos, além dos Negros do Riacho, há a comunidade das Queimadas, conhecida como "Negros do Totoró", formada por uma população de maioria negra que ocupa há mais de um século terras herdadas dos antigos 
(RIO GRANDE DO NORTE, 2006).

A arte do barro está impregnada na identidade da comunidade, ou seja, é suporte de memória (SILVIA, 2009). Essa arte aparece para as pessoas que não são da comunidade como uma marca culturalmente positiva - ainda que questionem a qualidade da louça produzida na comunidade. A produção teve início desde a formação da comunidade, segundo a descendente mais antiga de "Trajano Passarinho" e ex-artesãs. Ela aprendeu o ofício com a sua mãe, que por sua vez aprendeu com a sua avó, essa, mulher de Trajano. Logo, os ensinamentos foram passados ao longo das gerações.

A produção ceramista sempre foi realizada na sua maioria por mulheres, em núcleos familiares e consiste em louças e objetos de decoração em pequena escala. Entretanto, já sofreu interferências no processo de produção com a inserção de tornos para modelagem segundo as próprias artesãs. As louceiras deveriam reaprender a fazer a louça em uma máquina e esquecerem os ensinamentos dos mais velhos, repensando a estética das peças. Contudo, não obtiveram sucesso e as artesãs mantiveram as técnicas tradicionais.

As figuras 2 e 3 mostram peças produzidas pelas artesãs e o processo de preparação do barro, respectivamente:

Figura 2: pelas produzidas pelas artesãs.

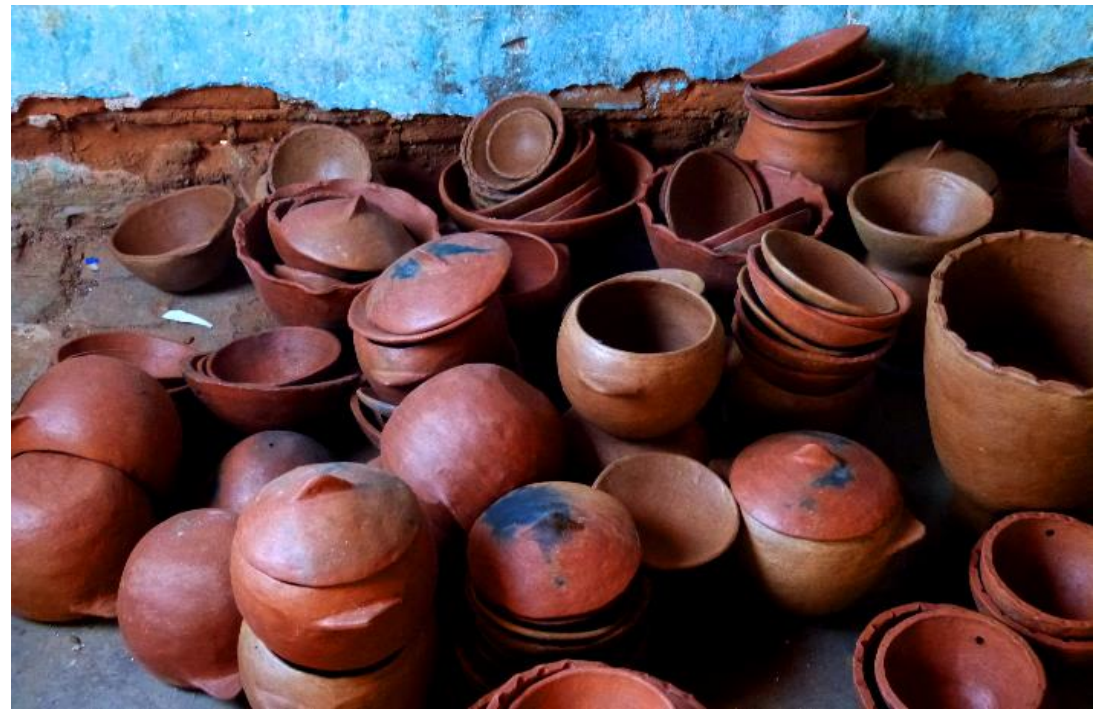

Fonte: Autora, 2017. 
Figura 3: pelas processo de preparação do barro.

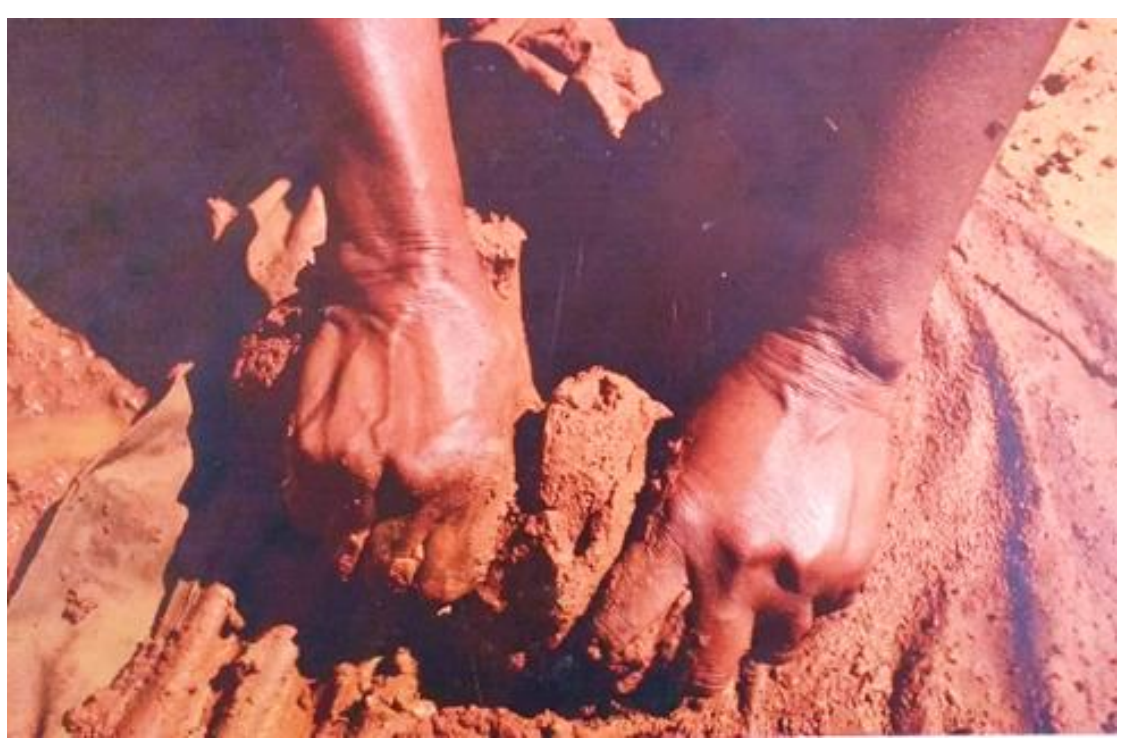

Fonte: Autora, 2017.

\subsection{Os vários caminhos: desenvolvendo ações em conjunto}

A conduta metodológica para a realização das ações esteve focada no indivíduo e no produto. Contou com abordagens flexíveis orientadas para o desenvolvimento de projetos abertos, complexos que envolvem várias áreas do conhecimento. Neste caminho, para estruturação levouse em conta ferramentas que tratam da correspondência entre antropologia e design, design e etnografia, design e artesanato e métodos da ergonomia, visto que esta é inseparável do processo projetual. Como citado o estudo do corpo não está dissociado da cultura, portanto, existe uma relação entre antropologia, design e ergonomia que é trabalhada na segunda ação escolhida. Para melhor compreensão, a tabela 1 a seguir, apresenta os métodos e ferramentas e cada autor utilizado. 
Tabela 1: Autores, métodos e ferramentas.

\begin{tabular}{|l|l|l|l|}
\hline \multicolumn{1}{|c|}{ DESIGN ETNOGRÁFICO } & \multicolumn{1}{|c|}{ ERGONOMIA } & \multicolumn{1}{|c|}{$\begin{array}{c}\text { DESIGN } \\
\text { ANTHROPOLOGY }\end{array}$} & \multicolumn{1}{|c|}{$\begin{array}{c}\text { DESIGN E } \\
\text { ARTESANATO }\end{array}$} \\
\hline $\begin{array}{l}\text { O'GRADY (2006) } \\
\text { Observação | Revisão } \\
\text { bibliográfica | Inquirição } \\
\text { | Antropologia Visual | } \\
\begin{array}{l}\text { Painel Semântico | } \\
\text { Sketching }\end{array}\end{array}$ & $\begin{array}{l}\text { MORAES E MONT'ALVÃo (2009) } \\
\text { Observação | Inquirição | } \\
\text { Detalhamento das atividades da } \\
\text { tarefa | Categorização dos problemas } \\
\text { ergonômicos | Protótipos }\end{array}$ & $\begin{array}{l}\text { GUNN E } \\
\text { DONOVAN (2013) } \\
\text { Provótipos }\end{array}$ & $\begin{array}{l}\text { KRÇ̃̃es: RECONHCER e } \\
\text { DESENVOLVER }\end{array}$ \\
& $\begin{array}{l}\text { IDA (2005) } \\
\text { Iiagrama de áreas dolorosas }\end{array}$ & \\
\hline
\end{tabular}

Fonte: Autora, 2017

Foram escolhidas duas ações em Design propostas por Krucken (2009) para serem desenvolvidas na CQNR. A primeira é a RECONHECER as qualidades do produto e do território, realizada ainda durante a participação no grupo de pesquisa ECOAR. Essa ação é primordial para a aplicação das outras ações propostas por Krucken (2009), a mesma está relacionada à correspondência entre antropologia e design e também à pesquisa etnográfica.

A segunda ação aplicada foi a de DESENVOLVER novos produtos que respeitem a vocação e valorizem o território, realizada na disciplina de Projeto de Produto VI. Essa ação só foi realizada após a conclusão da primeira, visto que as dificuldades identificadas por meio da fala das artesãs na produção artesanal nos levaram a decidir em qual fase do processo de produção poderíamos interferir. Sendo assim, encontrada dificuldades em todas as fases da produção que são: extração, preparação e modelagem do barro, finalização e queima das peças, foi decido focar na extração do barro, devido ao tempo hábil para desenvolvimento do projeto e também em razão de ser o início de todo o processo de reprodução. A extração da sua própria argila é para a ceramista rural parte essencial do seu processo de trabalho e base para tudo o que acontecerá depois. Portanto, as ferramentas e métodos foram aplicados voltados para o desenvolvimento de um artefato que potencialize e melhore as condições físicas e trabalho das artesãs na tarefa de extração do barro contribuindo para a valorização da produção artesanal da comunidade.

\subsection{Resultado das ações}


A ação consistiu na primeira etapa do projeto nas qual é feita a imersão por meio das ferramentas do design etnográfico, para conhecer e compreender o contexto sociocultural da comunidade, as artesãs e o objeto de estudo, a produção de cerâmica artesanal. Desse modo, foram traçados valores e a identidade dos atores envolvidos por meio da produção ceramista e sua história e cultura. Bem como foram feitos os registros visuais a partir da ferramenta antropologia visual.

A segunda ação consisitiu na aplicação da ferramenta provótipos, provocando as artesãs a partir de perguntas, fazendo-as refletir e depois agir expressando-se visualmente e verbalmente. Também foram aplicadas as ferramentas ergonômicas para projeção do veículo de tração humana e as ferramentas sketching e protótipos. Após a produção dos protótipos foi validado com as artesãs para os possíveis ajustes que precisrão ser feitos no protótipo. A figuras 4 ilustra o carrinho.

Figura 4: Veículo de tração humana para as artesãs.
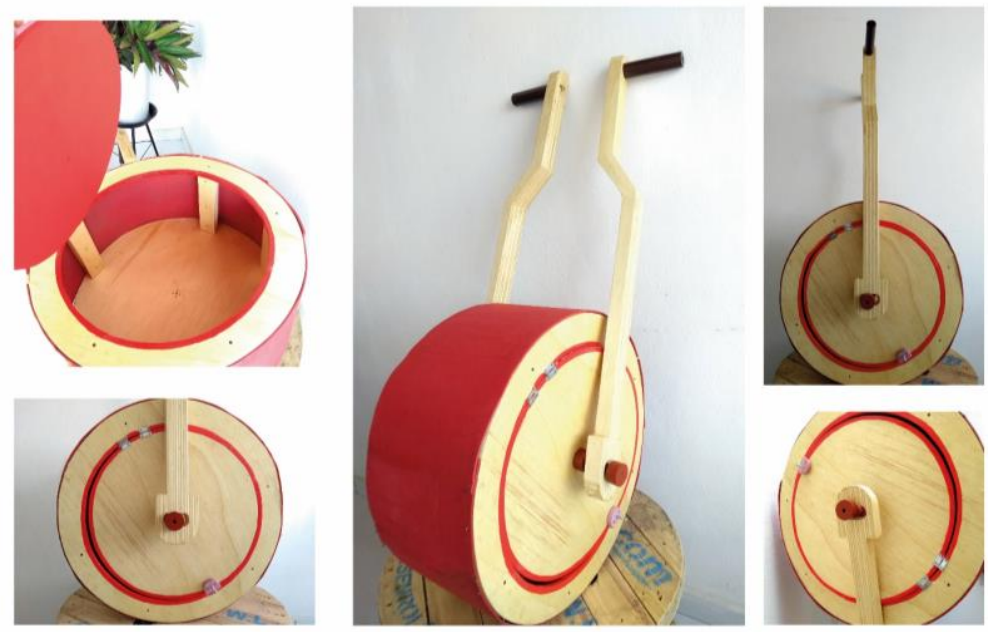

Fonte: Autora, 2017.

\section{Considerações finais}

A produção artesanal da cerâmica é um dos principais traços da identidade cultural da Comunidade Quilombola Negros do Riacho e o que ela proporciona às artesãs vai além do complemento de renda. O empoderamento feminino, construído por meio do artesanato fez com que essas mulheres conquistasse uma voz ativa dentro da família e da comunidade.

A partir da pesquisa em literatura e do trabalho de campo mediado pelas ferramentas do 
design etnográfico e do design anthropology, pode-se compreender como a antropologia e o design podem criar um campo híbrido e rico em conhecimento para desenvolvimento de ações em design e valorização do artesanato. Bem como, é possível compreender como essas ferramentas contribuem na construção social e na reflexão e tomada de decisões no processo de projeto.

Nessa perspectiva, o trabalho também abre espaço para continuidade da pesquisa teórica sobre outras práticas do design como os processos colaborativos e design social. Além disso, podem ser desenvolvidas outras ações em design propostas pelos autores estudados como Krucken (2009) e Borges (2009). Podem ser desenvolvidas ações como construção de uma marca para as artesãs como forma de comunicar o produto artesanal e o território. Melhoria nas técnicas e em outras tarefas do processo de produção. Bem como a consolidação de redes para o desenvolvimento econômico da comunidade.

É importante ressaltar que o projeto desenvolvido pode ser compartilhado e reproduzido em outros grupos de artesãos proporcionando uma oportunidade de vivenciar experiências orientadas pelo design e a antropologia para a construção de um bem maior, a visibilidade do seu fazer com a valorização do artesanato.

\section{Referências}

ALVES, C. M. Poéticas do porvir: Os Estudos de Tendências como Prática entre o Design e a Antropologia. Dissertação (Mestrado em Design) - Universidade Federal de Santa Catarina, Florianópolis, 2016.

ALMEIDA, Juliana Donato de. Modelagem situada de uma atividade tradicional: o caso da oficina de desenho de renda de Bilros. Dissertação (Mestrado em Engenharia de Produção) - Universidade Federal do Rio Grande do Norte, Natal, 2010. 184f. ; il.

ANASTASSAKIS, Zoy. Antropologia do Design: observações da prática antropológica pelo design hoje. In: 28a Reunião Brasileira de Antropologia. São Paulo, 2012.

. Design e antropologia como práticas de correspondência. In: Debulha - 8a Semana

Acadêmica de Design da UFRN. Natal, 2017.

Design e antropologia: desafios em busca de um diálogo promissor. In: P\&D Design

- Congresso Brasileiro de Pesquisa e Desenvolvimento em Design. Maranhão, 2012.

ANASTASSAKIS, Z. IBARRA, M.C. PORTO, M. C.U. Design e antropologia: novas interações para pensar as questões sociais. [28 de julho de 2016] Rio Grande do Sul: Instituto Humanitas Unisinos. Entrevista concedida a Leslie Chaves e Patricia Fachin.

ANASTASSAKIS, Z.; PAES, L. Reflexões sobre processos colaborativos de design. In: 12 P\&D Design - Congresso Brasileiro de Pesquisa e Desenvolvimento em Design. Belo Horizonte, 2016. 
GONÇALVES, Marco Antonio. Traduzir o outro. Etnografia e semelhança. Rio de Janeiro: 7Letras, 2010.

GUNN, Wendy; DONOVAN, Jared. "Design Athropology: A Introduction". In: Design and Anthropology. Ed: Wendy Gunn and Jared Donovan. New York: Routledge, 2016.

GUNN, Wendy; DONOVAN, Jared. "Moving from Objects to Possibilities". In: GUNN, Wendy; DONOVAN, Jared. (Eds.). Design and Anthropology. New York: Routledge, 2016.

IIDA, Itiro. Ergonomia: projeto e produção.São Paulo: Edgard Blücher, 2005.

KRUCKEN, Lia. Design e território: valorização de identidades e produtos locais. São Paulo: Studio Nobel, 2009.

LAPLANTINE, François. Aprender antropologia. São Paulo: Brasiliense, 2003.

LARAIA, Roque de Barros. Cultura: um conceito antropológico. Rio de Janeiro: Jorge Zahar, 2001.

MOURA, M. Poéticas do design contemporâneo: a reinvenção do objeto. III Seminário Nacional de Pesquisa em Cultura Visual, 2010, Goiânia. Anais do III Seminário Nacional de Pesquisa em Cultura Visual. Goiânia: Editora da UFG, 2010

MORAES, A. MONT'ALVÃO, C. Ergonomia: conceitos e aplicações. Riode Janeiro: 2AB, 2009.

MURPHY, Keith M; MARCUS, George E. "Epilogue: Ethnography and Design, Ethnography in Design ... Ethnography by Design." In: In: Design Anthropology: Theorie and Practice. Ed: Gunn, Wendy; Otto, Ton; Smith, Rachel. p. 175-198. Bloosmbury, 2013.

NORONHA, R. et al. Design, artesanato e políticas públicas. Artigo publicado na VII Jornada de Internacional de Políticas Públicas. Maranhão, 2015.

RIO GRANDE DO NORTE. Projeto Dignidade. - Negros do Riacho. Natal: Governo do Estado do Rio Grande do Norte, 2006.

O'GRADY, Jenn \& K.V. A Designer's research manual. Succeed in Design by knowing your clients and what they really need. Berverly: ed. RockPort, 2006.

PORTO, M. C. U. IBARRA, M. C. ANASTASSAKIS,Z. Design Anthropology na transformação colaborativa de espaços públicos. Estudos em Design | Revista (online). Rio de Janeiro: v. 24 | n. 3 [2016], p. $76-87$ | ISSN 1983-196X

SILVIA, Joelma Tito da. Quilombo no Rio Grande do Norte: história e legislação. In: SIMPÓSIO NACIONAL DE HISTÓRIA, 25., 2009, Fortaleza. Anais do XXV Simpósio Nacional de História - História e Ética. Fortaleza: ANPUH, 2009. 